Research Article

\title{
Topological Structure of Vague Soft Sets
}

\author{
Chang Wang and Yaya Li \\ School of Mathematics, Northwest University, Xian, Shaanxi 710127, China \\ Correspondence should be addressed to Chang Wang; cwang@nwu.edu.cn
}

Received 21 April 2014; Accepted 18 June 2014; Published 6 July 2014

Academic Editor: Gerd Teschke

Copyright (c) 2014 C. Wang and Y. Li. This is an open access article distributed under the Creative Commons Attribution License, which permits unrestricted use, distribution, and reproduction in any medium, provided the original work is properly cited.

\begin{abstract}
We introduce vague soft topological spaces which are defined over an initial universe with a fixed set of parameters. The notions of vague soft open sets, vague soft closed sets, vague soft interior, vague soft closure, and vague soft boundary are introduced and their basic properties and relations are investigated. Furthermore, with the help of examples they established that some properties of topological spaces and soft topological spaces do not hold in vague soft topological spaces. Vague soft connectedness and vague soft compactness are also studied.
\end{abstract}

\section{Introduction}

Researchers in economics, environmental science, social science, medical science, business, and many other fields deal daily with the complexities of modeling uncertain data. Classical methods are not always successful because the uncertainties appearing in these domains may be of various types. Fuzzy set theory [1], intuitionistic fuzzy set theory [2], vague set theory [3], interval mathematics [4], and other mathematical tools are well-known and often useful approaches to describing uncertainty. However, all of these theories have their own difficulties which have been pointed out in [5]. Molodtsov suggested that one reason for these difficulties may be due to the inadequacy of the parameterization tools of these theories. To overcome these difficulties, Molodtsov [5] introduced the concept of soft sets as a new mathematical tool for dealing with uncertainties that is free from the difficulties that have troubled the usual theoretical approaches. Since then, many researches have investigated soft sets and have established some significant conclusions. For example, Jun and Park [6] proposed the notion of soft ideals and idealistic soft BCK/BCI-algebras and constructed several examples. Majumdar and Samanta [7] further generalized the concept of fuzzy soft sets and some of their properties were studied, and relations on generalized fuzzy soft sets were also discussed by them. Maji et al. [8] introduced the concept of fuzzy soft sets by combining fuzzy sets and soft sets. By combining the vague set and the soft set, $\mathrm{Xu}$ et al. [9] introduced the notion of vague soft sets, derived its basic properties, and illustrated its potential applications. Wang and $\mathrm{Qu}[10]$ introduced the definitions of entropy, similarity measure, and distance measure of vague soft sets, and the relations between these measures are discussed in detail. About soft topology, Shabir and Naz [11] defined several basic notions on soft topology and studied many properties. Hussain and Ahmad [12] continued investigating the properties of soft topological spaces and strengthened the foundations of the theory of soft topological spaces. Tanay and Kandemir [13] introduced the concept of fuzzy soft topology and some of its structural properties are studied.

By definition, a soft set is a parameterized family of subsets of the universal set. In other words, a soft set is a mapping from a set of parameters to the power set of an initial universe set. In the real world, the difficulty is that the objects in the universal set may not precisely satisfy the problem's parameters, which usually represent some attributes, characteristics, or properties of the objects in the universal set. The concept of fuzzy soft sets proposed in [8] partially resolves this difficulty but falls short in dealing with additional complexity; that is, the mapping may be too vague. It is, therefore, desirable to extend soft set theory and fuzzy soft set theory using the concept of vague set theory. Vague set 
theory is actually an extension of fuzzy set theory and vague sets are regarded as a special case of context-dependent fuzzy sets. The basic concepts of vague set theory and its extensions, as well as some interesting applications, can be found in [1416]. Vague soft set theory makes descriptions of the object world more realistic, practical, and accurate, at least in some cases, making it a very promising tool. Since vague sets are equivalent to intuitionistic fuzzy sets [17], so vague soft sets are equivalent to intuitionistic fuzzy soft sets. Some scholars have studied intuitionistic fuzzy soft sets from different aspects. For example, Gunduz and Bayramov [18] introduced the concept of an intuitionistic fuzzy soft module and some operations on intuitionistic fuzzy soft sets were given; they also studied some of its basic properties. Jiang et al. [19] proposed the notion of the interval-valued intuitionistic fuzzy soft set, the complement, and/or union, intersection, and necessity, and possibility operations were defined on interval-valued intuitionistic fuzzy soft sets, and the basic properties of interval-valued intuitionistic fuzzy soft sets were discussed. They [20] also presented an adjustable approach to intuitionistic fuzzy soft sets based decision making by using level soft sets of intuitionistic fuzzy soft sets and gave some illustrative examples; the weighted intuitionistic fuzzy soft sets were introduced and its application to decision making was investigated. Zhang [21] proposed a novel approach to intuitionistic fuzzy soft set based decision making problems using rough set theory. However, there has been rather little work completed for topological structure in the context of intuitionistic fuzzy soft sets. The purpose of this paper is to further extend the concept of vague soft set theory proposed by $\mathrm{Xu}$ et al. in [9]. In this paper, the concept of vague soft topology is introduced and some of its structural properties are studied. Some results about vague soft connectedness and vague soft compactness are also investigated.

The rest of this paper is organized as follows. Section 2 recalls some basic concepts of vague sets, soft sets, and vague soft sets. In Section 3, we introduce the definitions of vague soft topology and some of its structural properties such as vague soft open sets, vague soft closed sets, vague soft interior, vague soft closure, and vague soft boundary are studied. The vague soft connectedness and vague soft compactness are also investigated. In the final section, some concluding comments are presented.

\section{Preliminaries}

In this section, we will recall several definitions and results which are necessary for our paper. They are stated as follows.

Definition 1 (see [3]). A vague set $A$ in the universe $U=$ $\left\{x_{1}, x_{2}, \ldots, x_{n}\right\}$ can be expressed by the following notion: $A=$ $\left\{\left(x_{i},\left[t_{A}\left(x_{i}\right), 1-f_{A}\left(x_{i}\right)\right]\right) \mid x_{i} \in U\right\}$; that is, $A\left(x_{i}\right)=\left[t_{A}\left(x_{i}\right), 1-\right.$ $f_{A}\left(x_{i}\right)$, and the condition $0 \leq t_{A}\left(x_{i}\right) \leq 1-f_{A}\left(x_{i}\right)$ should hold for any $x_{i} \in U$, where $t_{A}\left(x_{i}\right)$ is called the membership degree (true membership) of element $x_{i}$ to the vague set $A$, while $f_{A}\left(x_{i}\right)$ is the degree of nonmembership (false membership) of the element $x_{i}$ to the vague set $A$.
Definition 2 (see [3]). Let $A, B$ be two vague sets in the universe $U=\left\{x_{1}, x_{2}, \ldots, x_{n}\right\}$; then the union, intersection, and complement of vague sets are defined as follows:

$$
\begin{gathered}
A \cup B=\left\{\left(x_{i},\left[t_{A}\left(x_{i}\right) \vee t_{B}\left(x_{i}\right),\right.\right.\right. \\
\left.\left.\left.\left(1-f_{A}\left(x_{i}\right)\right) \vee\left(1-f_{B}\left(x_{i}\right)\right)\right]\right) \mid x_{i} \in U\right\}, \\
A \cap B=\left\{\left(x_{i},\left[t_{A}\left(x_{i}\right) \wedge t_{B}\left(x_{i}\right),\right.\right.\right. \\
\left.\left.\left.\left(1-f_{A}\left(x_{i}\right)\right) \wedge\left(1-f_{B}\left(x_{i}\right)\right)\right]\right) \mid x_{i} \in U\right\}, \\
A^{c}=\left\{\left(x_{i},\left[f_{A}\left(x_{i}\right), 1-t_{A}\left(x_{i}\right)\right]\right) \mid x_{i} \in U\right\} .
\end{gathered}
$$

Definition 3 (see [3]). Let $A, B$ be two vague sets in the universe $U=\left\{x_{1}, x_{2}, \ldots, x_{n}\right\}$. If $\forall x_{i} \in U, t_{A}\left(x_{i}\right) \leq t_{B}\left(x_{i}\right), 1-$ $f_{A}\left(x_{i}\right) \leq 1-f_{B}\left(x_{i}\right)$, then $A$ is called a vague subset of $B$, denoted by $A \subseteq B$, where $1 \leq i \leq n$.

Definition 4 (see [5]). Let $U$ be an initial universe set, $P(U)$ the power set of $U, E$ a set of parameters, and $A \subseteq E$. A pair $(F, A)$ is called a soft set over $U$, where $F$ is a mapping given by $F: A \rightarrow P(U)$.

Definition 5 (see [9]). Let $U$ be an initial universe set, $V(U)$ the set of all vague sets on $U, E$ a set of parameters, and $A \subseteq E$. A pair $(F, A)$ is called a vague soft set over $U$, where $F$ is a mapping given by $F: A \rightarrow V(U)$.

Definition 6 (see [9]). Let $(F, A)$ and $(G, B)$ be two vague soft sets over a universe $U$. If $A \subseteq B$ and for all $e \in A, F(e)$ is a vague subset of $G(e)$, then $(F, A)$ is called a vague soft subset of $(G, B)$. This relation is denoted by $(F, A) \subseteq(G, B)$.

Definition 7 (see [9]). Two vague soft sets $(F, A)$ and $(G, B)$ over a universe $U$ are said to be vague soft equal if $(F, A)$ is a vague soft subset of $(G, B)$ and $(G, B)$ is a vague soft subset of $(F, A)$. This relation is denoted by $(F, A)=(G, B)$.

Definition 8 (see [9]). Let $E=\left\{e_{1}, e_{2}, \ldots, e_{n}\right\}$ be a parameter set. The not set of $E$ denoted by $\neg E$ is defined by $\neg E=$ $\left\{\neg e_{1}, \neg e_{2}, \ldots, \neg e_{n}\right\}$, where $\neg e_{i}=$ not $e_{i}$.

Definition 9 (see [9]). The complement of vague soft $\operatorname{set}(F, A)$ is denoted by $(F, A)^{c}$ and is defined by $(F, A)^{c}=\left(F^{c}, \neg A\right)$, where $F^{c}: \neg A \rightarrow V(U)$ is a mapping given by $t_{F^{c}(\neg \alpha)}(x)=$ $f_{F(\alpha)}(x), 1-f_{F^{c}(\neg \alpha)}(x)=1-t_{F(\alpha)}(x), \forall \neg \alpha \in \neg A, x \in U$.

Clearly $\left(F^{c}\right)^{c}$ is the same as $F$ and $\left((F, A)^{c}\right)^{c}=(F, A)$.

Definition 10 (see [9]). A vague soft set $(F, A)$ over $U$ is said to be a null vague soft set denoted by $\widehat{\emptyset}$, if $\forall e \in A, t_{F(e)}(x)=$ $0,1-f_{F(e)}(x)=0, x \in U$.

Definition 11 (see [9]). A vague soft set $(F, A)$ over $U$ is said to be an absolute vague soft set denoted by $\widehat{U}$, if $\forall e \in$ $E, t_{F(e)}(x)=1,1-f_{F(e)}(x)=1, x \in U$. 
Definition 12 (see [9]). The union of two vague soft sets $(F, A)$ and $(G, B)$ over a universe $U$ is a vague soft set $(H, C)$, where $C=A \cup B$ and $\forall e \in C$,

$$
\begin{gathered}
t_{H(e)}(x)= \begin{cases}t_{F(e)}(x) & e \in A-B, x \in U, \\
t_{G(e)}(x) & e \in B-A, x \in U, \\
t_{F(e)}(x) \vee t_{G(e)}(x) & e \in A \cap B, x \in U,\end{cases} \\
1-f_{H(e)}(x) \\
= \begin{cases}1-f_{F(e)}(x) & e \in A-B, x \in U, \\
1-f_{G(e)}(x) & e \in B-A, x \in U, \\
\left(1-f_{F(e)}(x)\right) \vee\left(1-f_{G(e)}(x)\right) & e \in A \cap B, x \in U .\end{cases}
\end{gathered}
$$

We denote it by $(F, A) \cup(G, B)=(H, C)$.

Definition 13 (see [9]). The intersection of two vague soft sets $(F, A)$ and $(G, B)$ over a universe $U$ is a vague soft set $(H, C)$, where $C=A \cup B$ and $\forall e \in C$,

$$
\begin{gathered}
t_{H(e)}(x)= \begin{cases}t_{F(e)}(x) & e \in A-B, x \in U, \\
t_{G(e)}(x) & e \in B-A, x \in U, \\
t_{F(e)}(x) \wedge t_{G(e)}(x) & e \in A \cap B, x \in U,\end{cases} \\
1-f_{H(e)}(x) \\
= \begin{cases}1-f_{F(e)}(x) & e \in A-B, x \in U, \\
1-f_{G(e)}(x) & e \in B-A, x \in U, \\
\left(1-f_{F(e)}(x)\right) \wedge\left(1-f_{G(e)}(x)\right) & e \in A \cap B, x \in U .\end{cases}
\end{gathered}
$$

We denote it by $(F, A) \cap(G, B)=(H, C)$.

Proposition 14 (see [9]). If $(F, A)$ and $(G, B)$ are two vague soft sets over a universe $U$, then
(1) $((F, A) \cup(G, B))^{c}=(F, A)^{c} \cap(G, B)^{c}$,
(2) $((F, A) \cap(G, B))^{c}=(F, A)^{c} \cup(G, B)^{c}$.

\section{Vague Soft Topological Spaces}

Let $X$ be an initial universe set, and let $E$ be the nonempty set of parameters.

Definition 15. Let $\tau$ be the collection of vague soft sets over $X$; then $\tau$ is said to be a vague soft topology on $X$ if

(1) $\widehat{\emptyset}, \widehat{X}$ belong to $\tau$,

(2) the union of any number of vague soft sets in $\tau$ belongs to $\tau$,

(3) the intersection of any two vague soft sets in $\tau$ belongs to $\tau$.

The triplet $(X, \tau, E)$ is called a vague soft topological space over $X$.

Definition 16. Let $(X, \tau, E)$ be a vague soft topological space over $X$; then the members of $\tau$ are said to be vague soft open sets in $X$.
Definition 17. Let $(X, \tau, E)$ be a vague soft topological space over $X$. A vague soft set $(F, E)$ over $X$ is said to be a vague soft closed set in $X$, if its complement $(F, E)^{c}$ belongs to $\tau$.

Proposition 18. Let $\left\{\tau_{k} \mid k \in K\right\}$ be a family of vague soft topologies on $X$; then $\bigcap_{k \in K} \tau_{k}$ is a vague soft topology on $X$.

Proof. (1) $\widehat{\emptyset}$ and $\widehat{X}$ belong to $\bigcap_{k \in K} \tau_{k}$.

(2) Let $\left\{\left(F_{i}, E\right) \mid i \in I\right\} \subseteq \bigcap_{k \in K} \tau_{k}$. Then for all $i \in I$, $\left(F_{i}, E\right) \in \tau_{k}$, so $\bigcup_{i \in I}\left(F_{i}, E\right) \in \tau_{k}$. Thus $\bigcup_{i \in I}\left(F_{i}, E\right) \in \bigcap_{k \in K} \tau_{k}$.

(3) Let $(F, E),(G, E) \in \bigcap_{k \in K} \tau_{k}$. Then for all $k \in K$, $(F, E),(G, E) \in \tau_{k}$. Since $((F, E) \cap(G, E)) \in \tau_{k}$, so $((F, E) \cap$ $(G, E)) \in \bigcap_{k \in K} \tau_{k}$.

Definition 19. Let $\left(X, \tau_{1}, E\right)$ and $\left(X, \tau_{2}, E\right)$ be two vague soft topological spaces over the same universe $X$. If each vague soft set $(F, E) \in \tau_{1}$ is in $\tau_{2}$, then $\tau_{2}$ is called vague soft finer than $\tau_{1}$, or $\tau_{1}$ is vague soft coarser than $\tau_{2}$.

Proposition 20. Let $\left\{\tau_{k} \mid k \in K\right\}$ be a family of all vague soft topologies on $X$; then $\bigcap_{k \in K} \tau_{k}$ is the coarsest vague soft topology on $X$.

Proof. $\bigcap_{k \in K} \tau_{k}$ is a vague soft topology on $X$ by Proposition 18. If each vague soft set $(F, E) \in \bigcap_{k \in K} \tau_{k}$, then $(F, E) \in$ $\tau_{k}$ for all $k \in K$. Hence $\bigcap_{k \in K} \tau_{k}$ is the coarsest vague soft topology on $X$.

Remark 21. Let $\left(X, \tau_{1}, E\right)$ and $\left(X, \tau_{2}, E\right)$ be two vague soft topological spaces over the same universe $X$; then $\left(X, \tau_{1} \cup\right.$ $\left.\tau_{2}, E\right)$ may not be a vague soft topological space over $X$.

Example 22. Let $X=\{a, b, c\}, E=\left\{e_{1}, e_{2}\right\}$ and $\tau_{1}=$ $\{\widehat{\emptyset}, \widehat{X},(F, E)\}, \tau_{2}=\{\widehat{\emptyset}, \widehat{X},(G, E)\}$ be two vague soft topologies defined on $X$ where $(F, E),(G, E)$ are vague soft sets over $X$, defined as follows:

$$
\begin{aligned}
& F\left(e_{1}\right)=\left\{\frac{[0.1,0.8]}{a}, \frac{[0.3,0.9]}{b}, \frac{[0.7,0.8]}{c}\right\}, \\
& F\left(e_{2}\right)=\left\{\frac{[0.2,0.5]}{a}, \frac{[0.5,0.6]}{b}, \frac{[0.8,1]}{c}\right\}, \\
& G\left(e_{1}\right)=\left\{\frac{[0,0.9]}{a}, \frac{[0.4,1]}{b}, \frac{[0,0]}{c}\right\}, \\
& G\left(e_{2}\right)=\left\{\frac{[0.3,0.6]}{a}, \frac{[0.4,0.7]}{b}, \frac{[0.6,0.8]}{c}\right\} .
\end{aligned}
$$

Now, $\tau_{1} \cup \tau_{2}=\{\widehat{\emptyset}, \widehat{X},(F, E),(G, E)\}$.

If we take $(F, E) \cup(G, E)=(H, E),(F, E) \cap(G, E)=(P, E)$, then

$$
\begin{aligned}
& H\left(e_{1}\right)=\left\{\frac{[0.1,0.9]}{a}, \frac{[0.4,1]}{b}, \frac{[0.7,0.8]}{c}\right\}, \\
& H\left(e_{2}\right)=\left\{\frac{[0.3,0.6]}{a}, \frac{[0.5,0.7]}{b}, \frac{[0.8,1]}{c}\right\},
\end{aligned}
$$




$$
\begin{aligned}
& P\left(e_{1}\right)=\left\{\frac{[0,0.8]}{a}, \frac{[0.3,0.9]}{b}, \frac{[0,0]}{c}\right\}, \\
& P\left(e_{2}\right)=\left\{\frac{[0.2,0.5]}{a}, \frac{[0.4,0.6]}{b}, \frac{[0.6,0.8]}{c}\right\} .
\end{aligned}
$$

$(H, E) \notin \tau_{1} \cup \tau_{2},(P, E) \notin \tau_{1} \cup \tau_{2}$, so $\left(X, \tau_{1} \cup \tau_{2}, E\right)$ is not a vague soft topological space on $X$.

Definition 23. Let $(X, \tau, E)$ be a vague soft topological space, and let $(F, E)$ be a vague soft set over $X$. Then vague soft interior of $(F, E)$, denoted by $(F, E)^{\circ}$, is defined as the union of all vague soft open sets contained in $(F, E)$.

Clearly, $(F, E)^{\circ}$ is the largest vague soft open set contained in $(F, E)$.

Theorem 24. Let $(X, \tau, E)$ be a vague soft topological space over $X$, and let $(F, E)$ and $(G, E)$ be two vague soft sets over $X$. Then the following properties hold:

(1) $\widehat{\emptyset}^{\circ}=\widehat{\emptyset}$ and $\widehat{X}^{\circ}=\widehat{X}$;

(2) $(F, E)^{\circ} \subseteq(F, E)$;

(3) $(F, E)$ is a vague soft open set if and only if $(F, E)^{\circ}=$ $(F, E)$;

(4) $\left((F, E)^{\circ}\right)^{\circ}=(F, E)^{\circ}$;

(5) $(F, E) \subseteq(G, E)$ implies $(F, E)^{\circ} \subseteq(G, E)^{\circ}$;

(6) $(F, E)^{\circ} \cap(G, E)^{\circ}=((F, E) \cap(G, E))^{\circ}$.

Proof. (1) and (2) are obvious.

$(3) \Rightarrow$ If $(F, E)$ is a vague soft open set, then $(F, E) \subseteq$ $(F, E)^{\circ}$. Since $(F, E)^{\circ} \subseteq(F, E)$ by part $(2)$, so $(F, E)=(F, E)^{\circ}$.

$\Leftarrow$ Suppose that $(F, E)=(F, E)^{\circ}$. Since $(F, E)^{\circ}$ is a vague soft open set, so $(F, E)$ is a vague soft open set.

(4) Since $(F, E)^{\circ}$ is a vague soft open set, we have $\left((F, E)^{\circ}\right)^{\circ}=(F, E)^{\circ}$ by part (3).

(5) If $(F, E) \subseteq(G, E)$, then $(F, E)^{\circ} \subseteq(F, E) \subseteq(G, E)$. $(F, E)^{\circ}$ is a vague soft open set contained in $(G, E)$, so $(F, E)^{\circ} \subseteq$ $(G, E)^{\circ}$ by Definition 23.

(6) Since $((F, E) \cap(G, E)) \subseteq(F, E),((F, E) \cap(G, E)) \subseteq$ $(G, E)$, so $((F, E) \cap(G, E))^{\circ} \subseteq(F, E)^{\circ},((F, E) \cap(G, E))^{\circ} \subseteq$ $(G, E)^{\circ}$ by part (5). Thus $((F, E) \cap(G, E))^{\circ} \subseteq(F, E)^{\circ} \cap$ $(G, E)^{\circ}$. Since $\left((F, E)^{\circ} \cap(G, E)^{\circ}\right) \subseteq((F, E) \cap(G, E))$, so $\left((F, E)^{\circ} \cap(G, E)^{\circ}\right)^{\circ} \subseteq((F, E) \cap(G, E))^{\circ}$ by part $(5) .(F, E)^{\circ} \cap$ $(G, E)^{\circ}$ is a vague soft open set; then $\left((F, E)^{\circ} \cap(G, E)^{\circ}\right)^{\circ}=$ $(F, E)^{\circ} \cap(G, E)^{\circ}$. Hence $(F, E)^{\circ} \cap(G, E)^{\circ}=((F, E) \cap(G, E))^{\circ}$.

Definition 25. Let $(X, \tau, E)$ be a vague soft topological space, and let $(F, E)$ be a vague soft set over $X$. Then vague soft closure of $(F, E)$, denoted by $\overline{(F, E)}$, is defined as the intersection of all vague soft closed sets containing $(F, E)$.

Clearly, $\overline{(F, E)}$ is the smallest vague soft closed set containing $(F, E)$.
Theorem 26. Let $(X, \tau, E)$ be a vague soft topological space over $X$, and let $(F, E)$ and $(G, E)$ be two vague soft sets over $X$. Then the following properties hold:

(1) $\overline{\widehat{\emptyset}}=\widehat{\emptyset}$ and $\overline{\widehat{X}}=\widehat{X}$;

(2) $(F, E) \subseteq \overline{(F, E)}$;

(3) $(F, E)$ is a vague soft closed set if and only if $\overline{(F, E)}=$ $(F, E)$;

(4) $\overline{\overline{(F, E)}}=\overline{(F, E)}$;

(5) $(F, E) \subseteq(G, E)$ implies $\overline{(F, E)} \subseteq \overline{(G, E)}$;

(6) $\overline{(F, E)} \cup \overline{(G, E)}=\overline{(F, E) \cup(G, E)}$.

Proof. The proof is similar to the proof of Theorem 24 .

Theorem 27. Let $(X, \tau, E)$ be a vague soft topological space over $X$, and let $(F, E)$ be a vague soft set over $X$. Then the following properties hold:
(1) $\left((F, E)^{\circ}\right)^{c}=\overline{(F, E)^{c}}$;
(2) $(\overline{(F, E)})^{c}=\left((F, E)^{c}\right)^{\circ}$.

Proof. (1) Suppose that $\left\{\left(F_{i}, E\right) \mid i \in I\right\}$ is the family of all vague soft open sets contained in $(F, E)$; that is, $(F, E)^{\circ}=$ $\bigcup_{i \in I}\left(F_{i}, E\right)$. Then $\left\{\left(F_{i}, E\right)^{c} \mid i \in I\right\}$ is the family of all vague soft closed sets containing $(F, E)^{c}$; that is, $\overline{(F, E)^{c}}=$ $\bigcap_{i \in I}\left(F_{i}, E\right)^{c}$. Since $\left((F, E)^{\circ}\right)^{c}=\left(\bigcup_{i \in I}\left(F_{i}, E\right)\right)^{c}=\bigcap_{i \in I}\left(F_{i}, E\right)^{c}$ by Proposition $14(1)$, so $\left((F, E)^{\circ}\right)^{c}=\overline{(F, E)^{c}}$.

(2) Suppose that $\left\{\left(F_{i}, E\right) \mid i \in I\right\}$ is the family of all vague soft closed sets containing $(F, E)$; that is, $\overline{(F, E)}=\bigcap_{i \in I}\left(F_{i}, E\right)$. Then $\left\{\left(F_{i}, E\right)^{c} \mid i \in I\right\}$ is the family of all vague soft open sets contained in $(F, E)^{c}$; that is, $\left((F, E)^{c}\right)^{\circ}=\bigcup_{i \in I}\left(F_{i}, E\right)^{c}$. Since $(\overline{(F, E)})^{c}=\left(\bigcap_{i \in I}\left(F_{i}, E\right)\right)^{c}=\bigcup_{i \in I}\left(F_{i}, E\right)^{c}$ by Proposition 14 (2), so $\left(\overline{(F, E)}^{c}{ }^{c}=\left((F, E)^{c}\right)^{\circ}\right.$.

Definition 28. Let $(X, \tau, E)$ be a vague soft topological space, and let $(F, E)$ be a vague soft set over $X$. Then vague soft boundary of $(F, E)$, denoted by $(F, E)$, is defined as $(F, E)=$ $\overline{(F, E)} \cap \overline{(F, E)^{c}}$.

Clearly, the vague soft sets $(F, E)$ and $(F, E)^{c}$ have same vague soft boundary; that is, $\underline{(F, E)}=\underline{(F, E)^{c}}$.

Theorem 29. Let $(X, \tau, E)$ be a vague soft topological space over $X$, and let $(F, E)$ be a vague soft set over $X$. Then the following properties hold:
(1) $\underline{\widehat{\emptyset}}=\underline{\widehat{X}}=\widehat{\emptyset}$;

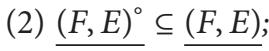
(3) $((F, E))^{c}=(F, E)^{\circ} \cup\left((F, E)^{c}\right)^{\circ}$. 
Proof. (1) is obvious.

(2) is as follows:

$$
\begin{aligned}
\underline{\underline{(F, E)^{\circ}}} & =\overline{(F, E)^{\circ}} \cap \overline{\left((F, E)^{\circ}\right)^{c}} \\
& =\overline{(F, E)^{\circ}} \cap \overline{\overline{(F, E)^{c}}} \quad(\text { by Theorem 27) } \\
& \subseteq \overline{(F, E)} \cap \overline{(F, E)^{c}}=\underline{(F, E) .}
\end{aligned}
$$

(3) is as follows:

$$
\begin{aligned}
(F, E)^{\circ} \cup\left((F, E)^{c}\right)^{\circ} \\
=\left(\left((F, E)^{\circ}\right)^{c}\right)^{c} \cup\left(\left(\left((F, E)^{c}\right)^{\circ}\right)^{c}\right)^{c} \\
=\left[\left((F, E)^{\circ}\right)^{c} \cap\left(\left((F, E)^{c}\right)^{\circ}\right)^{c}\right]^{c} \quad \text { (by Proposition 14) } \\
=\left[\overline{(F, E)^{c}} \cap \overline{(F, E)}\right]^{c} \quad(\text { by Theorem 27) } \\
=(\underline{(F, E)})^{c} .
\end{aligned}
$$

Remark 30. Let $(X, \tau, E)$ be a vague soft topological space over $X$, and let $(F, E)$ be a vague soft set over $X$. Then the following properties may not hold:

$$
\begin{aligned}
& \text { (1) } \overline{(F, E)}=(F, E)^{\circ} \cup \underline{(F, E)} ; \\
& \text { (2) }(F, E)^{\circ} \cap \underline{(F, E)}=\widehat{\emptyset} .
\end{aligned}
$$

Example 31. Let $X=\{a, b\}, E=\left\{e_{1}, e_{2}\right\}$, and $\tau=$ $\left\{\widehat{\emptyset}, \widehat{X},\left(F_{1}, E\right),\left(F_{2}, E\right)\right\}$ where $\left(F_{1}, E\right),\left(F_{2}, E\right)$ are vague soft sets over $X$, defined as follows:

$$
\begin{aligned}
& F_{1}\left(e_{1}\right)=\left\{\frac{[0.5,0.6]}{a}, \frac{[0.6,0.7]}{b}\right\}, \\
& F_{1}\left(e_{2}\right)=\left\{\frac{[0.5,0.7]}{a}, \frac{[0.7,0.8]}{b}\right\}, \\
& F_{2}\left(e_{1}\right)=\left\{\frac{[0.6,0.6]}{a}, \frac{[0.6,0.7]}{b}\right\}, \\
& F_{2}\left(e_{2}\right)=\left\{\frac{[0.6,0.8]}{a}, \frac{[0.7,0.8]}{b}\right\} .
\end{aligned}
$$

Then $\tau$ defines a vague soft topology on $X$ and $(X, \tau, E)$ is a vague soft topological space over $X$.

Let us take vague soft set $(F, E)$, defined as follows:

$$
\begin{aligned}
& F\left(e_{1}\right)=\left\{\frac{[0.8,0.9]}{a}, \frac{[0.8,0.8]}{b}\right\}, \\
& F\left(e_{2}\right)=\left\{\frac{[0.6,0.8]}{a}, \frac{[0.7,0.8]}{b}\right\} .
\end{aligned}
$$

Then $\overline{(F, E)}=\widehat{X}$

$$
\begin{aligned}
& \underline{(F, E)}=\left\{e_{1}=\left\{\frac{[0.4,0.4]}{a}, \frac{[0.3,0.4]}{b}\right\},\right. \\
& \left.e_{2}=\left\{\frac{[0.2,0.4]}{a}, \frac{[0.2,0.3]}{b}\right\}\right\}, \\
& (F, E)^{\circ}=\left\{e_{1}=\left\{\frac{[0.6,0.6]}{a}, \frac{[0.6,0.7]}{b}\right\},\right. \\
& \left.e_{2}=\left\{\frac{[0.6,0.8]}{a}, \frac{[0.7,0.8]}{b}\right\}\right\}, \\
& (F, E)^{\circ} \cup \underline{(F, E)}=\left\{e_{1}=\left\{\frac{[0.6,0.6]}{a}, \frac{[0.6,0.7]}{b}\right\},\right. \\
& \left.e_{2}=\left\{\frac{[0.6,0.8]}{a}, \frac{[0.7,0.8]}{b}\right\}\right\}, \\
& (F, E)^{\circ} \cap \underline{(F, E)}=\left\{e_{1}=\left\{\frac{[0.4,0.4]}{a}, \frac{[0.3,0.4]}{b}\right\},\right. \\
& \left.e_{2}=\left\{\frac{[0.2,0.4]}{a}, \frac{[0.2,0.3]}{b}\right\}\right\} \text {. }
\end{aligned}
$$

Hence $(F, E)^{\circ} \cup \underline{(F, E)} \neq \overline{(F, E)},(F, E)^{\circ} \cap \underline{(F, E)} \neq \widehat{\emptyset}$.

Theorem 32. Let $(X, \tau, E)$ be a vague soft topological space over $X$, and let $(F, E)$ be a vague soft set over $X$.

(1) If $(F, E) \cap \underline{(F, E)}=\widehat{\emptyset}$, then $(F, E)$ is a vague soft open set over $X$.

(2) If $(F, E)$ is a vague soft closed set over $X$, then $(F, E) \subseteq$ $(F, E)$.

Proof. (1) Let $(F, E) \cap(F, E)=\widehat{\emptyset}$. Then $(F, E) \cap \overline{(F, E)} \cap \overline{(F, E)^{c}}=$ $\widehat{\emptyset}$, or $(F, E) \cap \overline{(F, E)^{c}}=\widehat{\emptyset}$, or $\overline{(F, E)^{c}} \subseteq(F, E)^{c}$, which implies $(F, E)^{c}$ is a vague soft closed set. Hence $(F, E)$ is a vague soft open set.

(2) If $(F, E)$ is a vague soft closed set over $X$, then $\overline{(F, E)}=$ $(F, E)$, since $(F, E)=\overline{(F, E)} \cap \overline{(F, E)^{c}} \subseteq \overline{(F, E)}=(F, E)$; that is, $(F, E) \subseteq(F, \overline{E)}$.

Remark 33. Let $(X, \tau, E)$ be a vague soft topological space over $X$, and let $(F, E)$ be a vague soft set over $X$.

(1) If $(F, E)$ is a vague soft open set over $X$, then $(F, E) \cap$ $\underline{(F, E)}=\widehat{\emptyset}$ may not hold.

(2) If $(F, E) \subseteq(F, E)$, then $(F, E)$ may not be a vague soft closed set over $X$. 
Example 34. Let us consider the vague soft topological space $(X, \tau, E)$ over $X$ in Example 31. We take $(F, E)=\left(F_{1}, E\right)$ is a vague soft open set over $X$. Then

$$
\begin{gathered}
\overline{(F, E)}=\widehat{X}, \\
\overline{(F, E)^{c}}=\left\{e_{1}=\left\{\frac{[0.4,0.5]}{a}, \frac{[0.3,0.4]}{b}\right\},\right. \\
\left.e_{2}=\left\{\frac{[0.3,0.5]}{a}, \frac{[0.2,0.3]}{b}\right\}\right\}, \\
\underline{(F, E)}=\overline{(F, E)} \cap \overline{(F, E)^{c}} \\
=\left\{e_{1}=\left\{\frac{[0.4,0.5]}{a}, \frac{[0.3,0.4]}{b}\right\},\right. \\
\left.e_{2}=\left\{\frac{[0.3,0.5]}{a}, \frac{[0.2,0.3]}{b}\right\}\right\} .
\end{gathered}
$$

Hence $(F, E) \cap(F, E) \neq \widehat{\emptyset}$. We have $(F, E) \subseteq(F, E)$, but $(F, E)$ is not a vague soft closed set over $\overline{X \text {. }}$

Theorem 35. Let $(X, \tau, E)$ be a vague soft topological space over $X$, and let $(F, E)$ be a vague soft set over $X$. If $(F, E)=\widehat{\emptyset}$, then $(F, E)$ is a vague soft open set and vague soft closed set over $X$.

Proof. First we prove that $(F, E)$ is a vague soft open set over $X$. Consider $(F, E)=\widehat{\emptyset} \Rightarrow \overline{(F, E)} \cap \overline{(F, E)^{c}}=\widehat{\emptyset} \Rightarrow \overline{(F, E)} \cap$

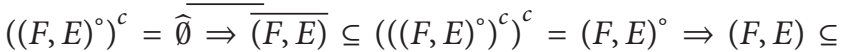
$(F, E)^{\circ} \Rightarrow(F, E)=(F, E)^{\circ}$. This implies that $(F, E)$ is a vague soft open set.

We now prove that $(F, E)$ is a vague soft closed set over $X$. Consider $(F, E)=\widehat{\emptyset} \Rightarrow \overline{(F, E)} \cap \overline{(F, E)^{c}}=\widehat{\emptyset} \Rightarrow \overline{(F, E)} \subseteq$ $\left(\overline{(F, E)^{c}}\right)^{c}=\left(\overline{F, E)^{\circ}} \Rightarrow \overline{(F, E)} \subseteq(F, E) \Rightarrow(F, E)=\overline{(F, E)}\right.$. This implies that $(F, E)$ is a vague soft closed set.

Remark 36. If $(F, E)$ is a vague soft open set and vague soft closed set over $X$, then $(F, E)$ may not be $\widehat{\emptyset}$.

Example 37. Let $X=\{a, b\}, E=\left\{e_{1}, e_{2}\right\}$, and $\tau=$ $\{\widehat{\emptyset}, \widehat{X},(F, E),(G, E)\}$ where $(F, E),(G, E)$ are vague soft sets over $X$, defined as follows:

$$
\begin{aligned}
& F\left(e_{1}\right)=\left\{\frac{[0.2,0.8]}{a}, \frac{[0.4,0.6]}{b}\right\}, \\
& F\left(e_{2}\right)=\left\{\frac{[0.3,0.7]}{a}, \frac{[0.5,0.5]}{b}\right\}, \\
& G\left(e_{1}\right)=\left\{\frac{[0.3,0.9]}{a}, \frac{[0.5,0.7]}{b}\right\}, \\
& G\left(e_{2}\right)=\left\{\frac{[0.4,0.8]}{a}, \frac{[0.6,0.7]}{b}\right\} .
\end{aligned}
$$

Then $\tau$ defines a vague soft topology on $X$ and $(X, \tau, E)$ is a vague soft topological space over $X$. We have $(F, E)$ is a vague soft open set and vague soft closed set over $X$, but $(F, E)=$ $(F, E) \neq \widehat{\emptyset}$.

Definition 38. A vague soft topological space $(X, \tau, E)$ is called strongly disconnected, if there exist vague soft open sets $(F, E) \neq \widehat{\emptyset}$ and $(G, E) \neq \widehat{\emptyset}$ such that $(F, E) \cup(G, E)=\widehat{X}$ and $(F, E) \cap(G, E)=\widehat{\emptyset}$.

Definition 39. A vague soft topological space $(X, \tau, E)$ is called strongly connected, if it is not vague soft strongly disconnected.

Definition 40. A vague soft topological space $(X, \tau, E)$ is called weakly disconnected, if there exists vague soft set $(F, E)$ which is both vague soft open set and vague soft closed set such that $\widehat{\emptyset} \neq(F, E) \neq \widehat{X}$.

Definition 41. A vague soft topological space $(X, \tau, E)$ is called weakly connected, if it is not vague soft weakly disconnected.

Theorem 42. Let $(X, \tau, E)$ be a vague soft topological space over $X$. If $(X, \tau, E)$ is strongly disconnected, then it is also weakly disconnected.

Proof. If $(X, \tau, E)$ is strongly disconnected, then there exist vague soft open sets $(F, E) \neq \widehat{\emptyset}$ and $(G, E) \neq \widehat{\emptyset}$ such that $(F, E) \cup$ $(G, E)=\widehat{X}$ and $(F, E) \cap(G, E)=\widehat{\emptyset}$. For any $e \in E$, we have $t_{F(e)}(x) \vee t_{G(e)}(x)=1,\left(1-f_{F(e)}(x)\right) \vee\left(1-f_{G(e)}(x)\right)=1$ and $t_{F(e)}(x) \wedge t_{G(e)}(x)=0,\left(1-f_{F(e)}(x)\right) \wedge\left(1-f_{G(e)}(x)\right)=0, x \in X$. When $t_{F(e)}(x)=1$, then $1-f_{F(e)}(x)=1$ and $t_{G(e)}(x)=0$, $1-f_{G(e)}(x)=0$. When $t_{G(e)}(x)=1$, then $1-f_{G(e)}(x)=1$ and $t_{F(e)}(x)=0,1-f_{F(e)}(x)=0$. Hence $(F, E)=(G, E)^{c}$; that is, $(F, E)$ is a vague soft set which is both vague soft open set and vague soft closed set such that $\widehat{\emptyset} \neq(F, E) \neq \widehat{X}$. Hence $(X, \tau, E)$ is weakly disconnected.

Remark 43. If $(X, \tau, E)$ is weakly disconnected, then it may not be strongly disconnected.

Example 44. Let $X=\{a, b\}, E=\left\{e_{1}, e_{2}\right\}$, and $\tau=$ $\left\{\widehat{\emptyset}, \widehat{X},\left(F_{1}, E\right),\left(F_{2}, E\right)\right\}$ where $\left(F_{1}, E\right)$ and $\left(F_{2}, E\right)$ are two vague soft sets over $X$, defined as follows:

$$
\begin{aligned}
& F_{1}\left(e_{1}\right)=\left\{\frac{[0.1,0.9]}{a}, \frac{[0.3,0.7]}{b}\right\}, \\
& F_{1}\left(e_{2}\right)=\left\{\frac{[0.4,0.6]}{a}, \frac{[0.2,0.8]}{b}\right\}, \\
& F_{2}\left(e_{1}\right)=\left\{\frac{[0.1,0.8]}{a}, \frac{[0.2,0.6]}{b}\right\}, \\
& F_{2}\left(e_{2}\right)=\left\{\frac{[0.3,0.6]}{a}, \frac{[0.2,0.7]}{b}\right\} .
\end{aligned}
$$

Then $\tau$ defines a vague soft topology on $X$ and $(X, \tau, E)$ is a vague soft topological space over $X$. Because $\left(F_{1}, E\right)$ is a vague soft set which is both vague soft open set and vague soft closed 
set such that $\widehat{\emptyset} \neq(F, E) \neq \widehat{X},(X, \tau, E)$ is weakly disconnected, but it is not strongly disconnected.

Theorem 45. $(X, \tau, E)$ is strongly disconnected if and only if there exist vague soft closed sets $(F, E) \neq \widehat{\emptyset}$ and $(G, E) \neq \widehat{\emptyset}$ such that $(F, E) \cup(G, E)=\widehat{X}$ and $(F, E) \cap(G, E)=\widehat{\emptyset}$.

Proof. $\Rightarrow \operatorname{If}(X, \tau, E)$ is strongly disconnected, then there exist vague soft open sets $(F, E) \neq \widehat{\emptyset}$ and $(G, E) \neq \widehat{\emptyset}$ such that $(F, E) \cup$ $(G, E)=\widehat{X}$ and $(F, E) \cap(G, E)=\widehat{\emptyset}$. Then $(F, E)^{c}$ and $(G, E)^{c}$ are vague soft closed sets such that $(F, E)^{c} \cup(G, E)^{c}=\widehat{X}$ and $(F, E)^{c} \cap(G, E)^{c}=\widehat{\emptyset}$.

$\Leftarrow$ The proof is similar to the above.

Theorem 46. $(X, \tau, E)$ is weakly disconnected if and only if there exist vague soft open sets $(F, E) \neq \widehat{\emptyset}$ and $(G, E) \neq \widehat{\emptyset}$ such that $(F, E)=(G, E)^{c}$.

Proof. $\Rightarrow$ If $(X, \tau, E)$ is weakly disconnected, then there exists vague soft set $(G, E)$ which is both vague soft open set and vague soft closed set such that $\widehat{\emptyset} \neq(G, E) \neq \widehat{X}$. Take $(F, E)=$ $(G, E)^{c}$; thus $(F, E)$ is a vague soft open set and $(F, E) \neq \widehat{\emptyset}$.

$\Leftarrow$ If there exist vague soft open sets $(F, E) \neq \widehat{\emptyset}$ and $(G, E) \neq \widehat{\emptyset}$ such that $(F, E)=(G, E)^{c}$, then $(F, E)$ is both vague soft open set and vague soft closed set. Since $(F, E) \neq \widehat{\emptyset}$, $(F, E)=(G, E)^{c} \neq \widehat{X}$, so $(X, \tau, E)$ is weakly disconnected.

Theorem 47. $(X, \tau, E)$ is weakly disconnected if and only if there exist vague soft sets $(F, E) \neq \widehat{\emptyset}$ and $(G, E) \neq \widehat{\emptyset}$ such that $(F, E)=(G, E)^{c},(G, E)=\left((F, E)^{\circ}\right)^{c},(F, E)=\left((G, E)^{\circ}\right)^{c}$.

Proof. $\Rightarrow \operatorname{If}(X, \tau, E)$ is weakly disconnected, then there exists vague soft set $(F, E)$ which is both vague soft open set and vague soft closed set such that $\widehat{\emptyset} \neq(F, E) \neq \widehat{X}$. Take $(G, E)=$ $(F, E)^{c}$; thus $(G, E)$ is both vague soft open set and vague soft closed set. Since $(F, E),(G, E)$ are vague soft open sets, $(G, E)=(G, E)^{\circ},(F, E)=(F, E)^{\circ}$. Hence $(G, E)=\left((F, E)^{\circ}\right)^{c}$, $(F, E)=\left((G, E)^{\circ}\right)^{c}$.

$\Leftarrow$ Suppose there exist vague soft set $(F, E) \neq \widehat{\emptyset}$ and $(G, E) \neq \widehat{\emptyset}$ such that $(F, E)=(G, E)^{c}$ and $(G, E)=\left((F, E)^{\circ}\right)^{c}$ and $(F, E)=\left((G, E)^{\circ}\right)^{c}$. Since $\left((F, E)^{\circ}\right)^{c}$ and $\left((G, E)^{\circ}\right)^{c}$ are vague soft closed sets, $(G, E)=\left((F, E)^{\circ}\right)^{c}$ and $(F, E)=$ $\left((G, E)^{\circ}\right)^{c}$ are vague soft closed sets. Since $(G, E)=(F, E)^{c}$, so $(G, E)$ is a vague soft open set. Thus, vague soft set $(G, E)$ is both vague soft open set and vague soft closed set such that $\widehat{\emptyset} \neq(G, E) \neq \widehat{X}$. Hence, $(X, \tau, E)$ is weakly disconnected.

Theorem 48. $(X, \tau, E)$ is weakly disconnected if and only if there exist vague soft sets $(F, E) \neq \widehat{\emptyset}$ and $(G, E) \neq \widehat{\emptyset}$ such that $(F, E)=(G, E)^{c},(G, E)=(\overline{(F, E)})^{c},(F, E)=(\overline{(G, E)})^{c}$.

Proof. The proof is similar to the proof of Theorem 47.

Definition 49. Let $(X, \tau, E)$ is a vague soft topological space over $X$. If a family $\left\{\left(F_{i}, E\right) \mid i \in I\right\}$ of vague soft open sets satisfies the condition $\bigcup_{i \in I}\left(F_{i}, E\right)=\widehat{X}$, then it is called a vague soft open cover of $X$. If a finite subfamily of a vague soft open cover is also a vague soft open cover of $X$, then it is called a finite subcover of $\left\{\left(F_{i}, E\right) \mid i \in I\right\}$.

Definition 50. A vague soft topological space $(X, \tau, E)$ is called vague soft compact if every vague soft open cover of $X$ has a finite subcover.

Example 51. Let $X=\{a, b\}, E=\left\{e_{1}, e_{2}\right\}$, and $\tau=$ $\left\{\widehat{\emptyset}, \widehat{X},\left(F_{n}, E\right)\right\}$ where $\left(F_{n}, E\right)$ is vague soft sets over $X$, defined as follows:

$$
\begin{gathered}
F_{n}\left(e_{1}\right) \\
=\left\{\frac{[1-1 / n, 1-1 /(n+1)]}{a}, \frac{[1-1 / n, 1-1 /(n+1)]}{b}\right\}, \\
F_{n}\left(e_{2}\right)=\left\{\frac{[1,1]}{a}, \frac{[1-1 / n, 1-1 /(n+1)]}{b}\right\} .
\end{gathered}
$$

Then $\tau$ defines a vague soft topology on $X$ and $(X, \tau, E)$ is a vague soft topological space over $X$.

$(X, \tau, E)$ is not vague soft compact, because the vague soft open cover $\left\{\left(F_{n}, E\right) \mid n \in N\right\}$ has no finite subcover.

Definition 52. Let $(X, \tau, E)$ be a vague soft topological space, and let $\left\{\left(F_{i}, E\right) \mid i \in I\right\}$ be a family of vague soft sets over $X .\left\{\left(F_{i}, E\right) \mid i \in I\right\}$ is said to satisfy the finite intersection property, if every finite subfamily $\left\{\left(F_{i}, E\right) \mid i=1,2, \ldots, n\right\}$ satisfies the condition $\bigcap_{i=1}^{n}\left(F_{i}, E\right) \neq \widehat{\emptyset}$.

Theorem 53. A vague soft topological space $(X, \tau, E)$ is vague soft compact if and only if every family $\left\{\left(F_{i}, E\right) \mid i \in I\right\}$ of vague soft closed sets which satisfies the finite intersection property has a nonempty intersection.

Proof. $\Rightarrow$ Let $\left\{\left(F_{i}, E\right) \mid i \in I\right\}$ be a family of vague soft closed sets which satisfies the finite intersection property. Suppose that $\bigcap_{i \in I}\left(F_{i}, E\right)=\widehat{\emptyset}$; then $\bigcup_{i \in I}\left(F_{i}, E\right)^{c}=\left(\bigcap_{i \in I}\left(F_{i}, E\right)\right)^{c}=\widehat{X}$, so $\left\{\left(F_{i}, E\right)^{c} \mid i \in I\right\}$ is a vague soft open cover of $X$. Since $(X, \tau, E)$ is vague soft compact, $\left\{\left(F_{i}, E\right)^{c} \mid i \in I\right\}$ has a finite subcover, denoted by $\left\{\left(F_{i}, E\right)^{c} \mid i=1,2, \ldots, n\right\}$. Thus, $\bigcap_{i=1}^{n}\left(F_{i}, E\right)=\left(\bigcup_{i=1}^{n}\left(F_{i}, E\right)^{c}\right)^{c}=\widehat{\emptyset}$, which is a contradiction. Hence, $\left\{\left(F_{i}, E\right) \mid i \in I\right\}$ has a nonempty intersection.

$\Leftarrow \operatorname{Let}\left\{\left(G_{i}, E\right) \mid i \in I\right\}$ is a vague soft open cover of $X$. Then $\left\{\left(G_{i}, E\right)^{c} \mid i \in I\right\}$ is a family of vague soft closed sets and $\bigcap_{i \in I}\left(G_{i}, E\right)^{c}=\left(\bigcup_{i \in I}\left(G_{i}, E\right)\right)^{c}=\widehat{\emptyset}$. Since every family of vague soft closed sets which satisfies the finite intersection property has a nonempty intersection, so $\left\{\left(G_{i}, E\right)^{c} \mid i \in I\right\}$ does not have the finite intersection property; that is, a subfamily $\left\{\left(G_{i}, E\right) \mid i=1,2, \ldots, n\right\}$ of $\left\{\left(G_{i}, E\right) \mid i \in I\right\}$ satisfies $\bigcap_{i=1}^{n}\left(G_{i}, E\right)^{c}=\widehat{\emptyset}$. Thus, $\bigcup_{i=1}^{n}\left(G_{i}, E\right)=\left(\bigcap_{i=1}^{n}\left(G_{i}, E\right)^{c}\right)^{c}=\widehat{X}$; that is, $\left\{\left(G_{i}, E\right) \mid i=1,2, \ldots, n\right\}$ is a finite subcover of $\left\{\left(G_{i}, E\right) \mid i \in I\right\}$. Hence, $(X, \tau, E)$ is vague soft compact.

Definition 54. Let $(X, \tau, E)$ be a vague soft topological space, and let $(F, E)$ be a vague soft set over $X$. If a family $\left\{\left(G_{i}, E\right) \mid\right.$ $i \in I\}$ of vague soft open sets satisfies the condition $(F, E) \subseteq$ $\bigcup_{i \in I}\left(G_{i}, E\right)$, then it is called a vague soft open cover of $(F, E)$. If a finite subfamily of a vague soft open cover is also a vague 
soft open cover of $(F, E)$, then it is called a finite subcover of $\left\{\left(G_{i}, E\right) \mid i \in I\right\}$.

Definition 55. A vague soft set $(F, E)$ is called vague soft compact if every vague soft open cover of $(F, E)$ has a finite subcover.

Theorem 56. A vague soft set $(F, E)$ is vague soft compact if and only if every family $\left\{\left(G_{i}, E\right) \mid i \in I\right\}$ of vague soft open sets with properties that, for any $e \in E, t_{F(e)}(x) \leq \bigvee_{i \in I} t_{G_{i}(e)}(x)$ and $1-f_{F(e)}(x) \leq \bigvee_{i \in I}\left(1-f_{G_{i}(e)}(x)\right), x \in X$, has a finite subfamily $\left\{\left(G_{i}, E\right) \mid i=1,2, \ldots, n\right\}$ such that $t_{F(e)}(x) \leq \bigvee_{i=1}^{n} t_{G_{i}(e)}(x)$ and $1-f_{F(e)}(x) \leq \bigvee_{i=1}^{n}\left(1-f_{G_{i}(e)}(x)\right), x \in X$.

Proof. It follows from Definitions 54 and 55.

\section{Conclusion}

Topology is an important and major area of mathematics. In this paper, we have introduced vague soft topological spaces which are defined over an initial universe with a fixed set of parameters. The notions and properties of vague soft open set, vague soft closed set, vague soft interior, vague soft closure, vague soft boundary, vague soft connectedness, and vague soft compactness are introduced and investigated. The findings in this paper will enhance and promote the further study on vague soft topological space to establish a general framework for practical application.

\section{Conflict of Interests}

The authors declare that there is no conflict of interests regarding the publication of this paper.

\section{Acknowledgments}

The authors would like to thank the anonymous referees for their constructive comments as well as helpful suggestions which helped in improving this paper significantly. The works described in this paper are supported by the National Natural Science Foundation of China under Grant nos. 11171271, 11326048; the Postdoctoral Science Foundation of China under Grant no. 2013M532079; and the Science Research Foundation of Northwest University under Grant no. 12NW04.

\section{References}

[1] L. A. Zadeh, "Fuzzy sets," Information and Computation, vol. 8, no. 3, pp. 338-353, 1965.

[2] K. T. Atanassov, "Intuitionistic fuzzy sets," Fuzzy Sets and Systems, vol. 20, no. 1, pp. 87-96, 1986.

[3] W. L. Gau and D. J. Buehrer, "Vague sets," IEEE Transactions on Systems, Man and Cybernetics, vol. 23, no. 2, pp. 610-614, 1993.

[4] K. T. Atanassov, "Operators over interval valued intuitionistic fuzzy sets," Fuzzy Sets and Systems, vol. 64, no. 2, pp. 159-174, 1994.

[5] D. Molodtsov, "Soft set theory-first results," Computers \& Mathematics with Applications, vol. 37, no. 4-5, pp. 19-31, 1999.
[6] Y. B. Jun and C. H. Park, "Applications of soft sets in ideal theory of BCK/BCI-algebras," Information Sciences, vol. 178, no. 11, pp. 2466-2475, 2008.

[7] P. Majumdar and S. K. Samanta, "Generalised fuzzy soft sets," Computers \& Mathematics with Applications, vol. 59, no. 4, pp. 1425-1432, 2010.

[8] P. K. Maji, R. Biswas, and A. R. Roy, "Fuzzy soft sets," Journal of Fuzzy Mathematics, vol. 9, no. 3, pp. 589-602, 2001.

[9] W. Xu, J. Ma, S. Wang, and G. Hao, "Vague soft sets and their properties," Computers \& Mathematics with Applications, vol. 59, no. 2, pp. 787-794, 2010.

[10] C. Wang and A. Qu, "Entropy, similarity measure and distance measure of vague soft sets and their relations," Information Sciences, vol. 244, pp. 92-106, 2013.

[11] M. Shabir and M. Naz, "On soft topological spaces," Computers \& Mathematics with Applications, vol. 61, no. 7, pp. 1786-1799, 2011.

[12] S. Hussain and B. Ahmad, "Some properties of soft topological spaces," Computers \& Mathematics with Applications, vol. 62, no. 11, pp. 4058-4067, 2011.

[13] B. Tanay and M. B. Kandemir, "Topological structure of fuzzy soft sets," Computers \& Mathematics with Applications, vol. 61, no. 10, pp. 2952-2957, 2011.

[14] S. M. Chen, "Similarity measures between vague sets and between elements," IEEE Transactions on Systems, Man, and Cybernetics B: Cybernetics, vol. 27, no. 1, pp. 153-158, 1997.

[15] D. H. Hong and C. H. Choi, "Multicriteria fuzzy decisionmaking problems based on vague set theory," Fuzzy Sets and Systems, vol. 114, no. 1, pp. 103-113, 2000.

[16] J. Ye, "Using an improved measure function of vague sets for multicriteria fuzzy decision-making," Expert Systems with Applications, vol. 37, no. 6, pp. 4706-4709, 2010.

[17] H. Bustince and P. Burillo, "Vague sets are intuitionistic fuzzy sets," Fuzzy Sets and Systems, vol. 79, no. 3, pp. 403-405, 1996.

[18] C. Gunduz and S. Bayramov, "Intuitionistic fuzzy soft modules," Computers \& Mathematics with Applications, vol. 62, no. 6, pp. 2480-2486, 2011.

[19] Y. Jiang, Y. Tang, Q. Chen, H. Liu, and J.-C. Tang, "Intervalvalued intuitionistic fuzzy soft sets and their properties," Computers \& Mathematics with Applications, vol. 60, no. 3, pp. 906918, 2010.

[20] Y. Jiang, Y. Tang, and Q. Chen, "An adjustable approach to intuitionistic fuzzy soft sets based decision making," Applied Mathematical Modelling: Simulation and Computation for Engineering and Environmental Systems, vol. 35, no. 2, pp. 824-836, 2011.

[21] Z. Zhang, "A rough set approach to intuitionistic fuzzy soft set based decision making," Applied Mathematical Modelling. Simulation and Computation for Engineering and Environmental Systems, vol. 36, no. 10, pp. 4605-4633, 2012. 


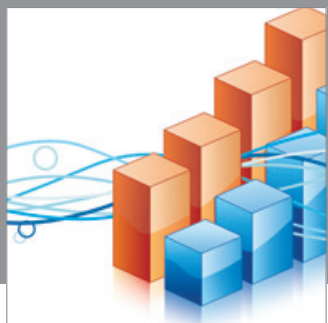

Advances in

Operations Research

mansans

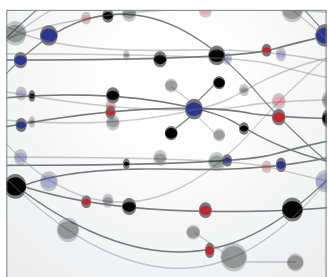

The Scientific World Journal
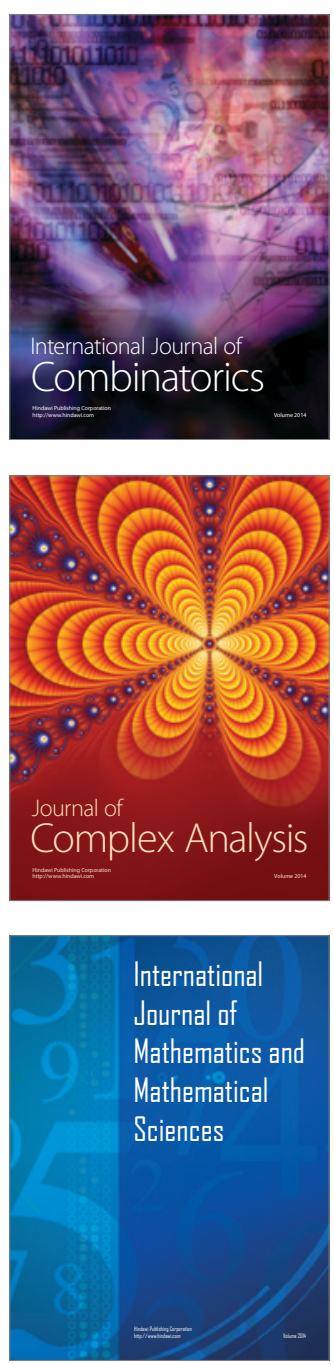
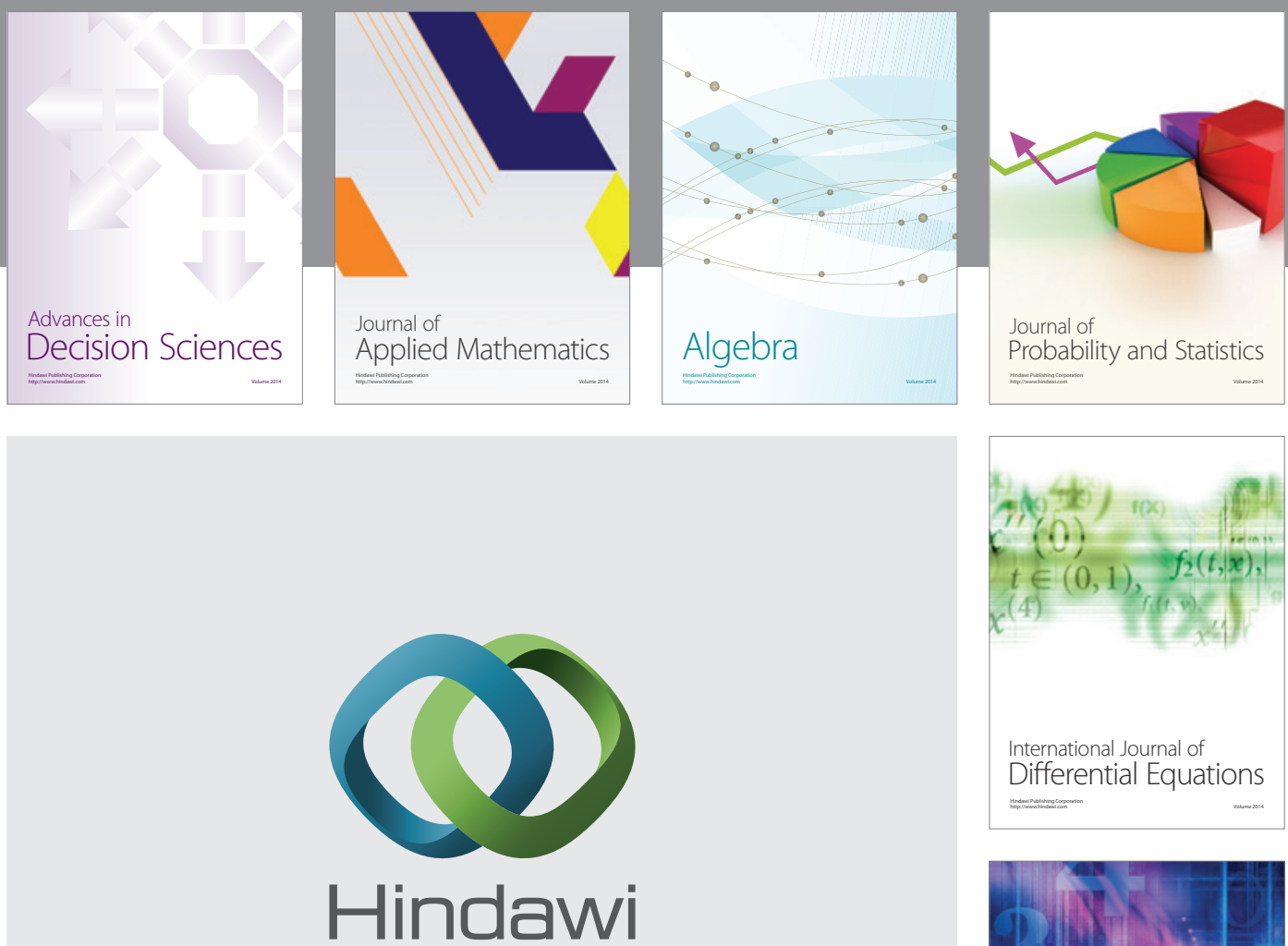

Submit your manuscripts at http://www.hindawi.com
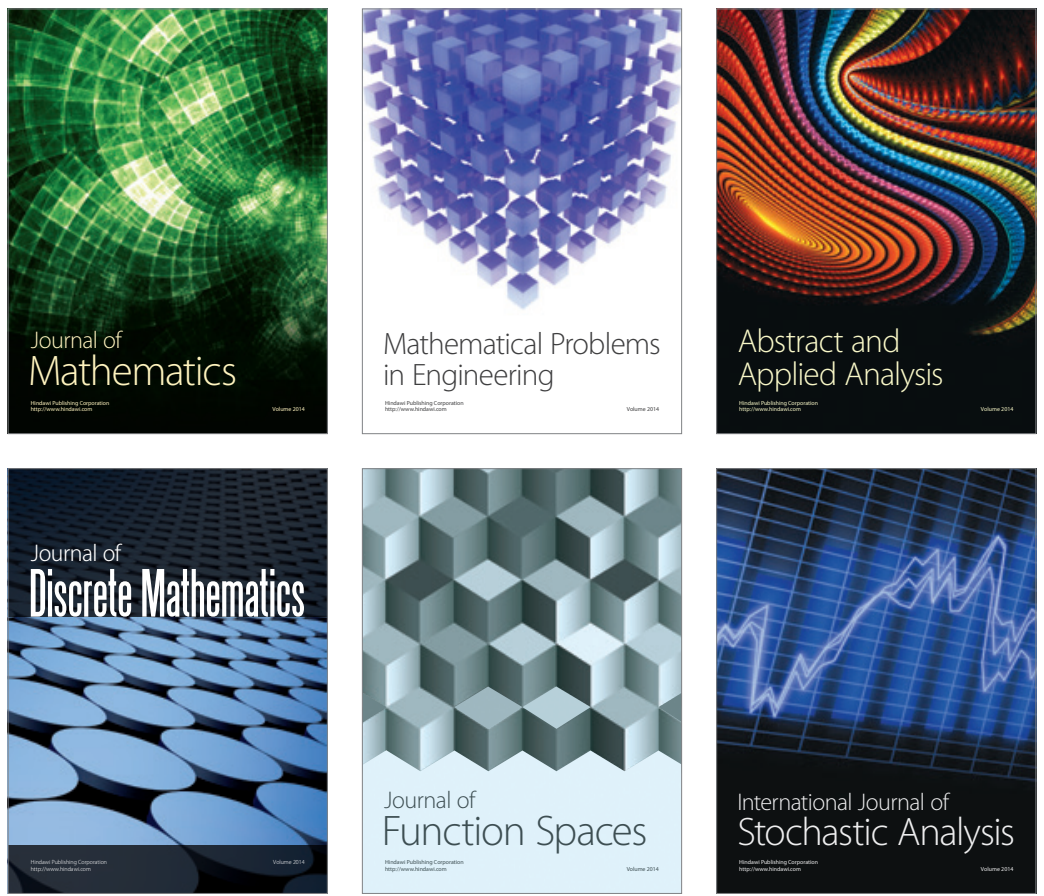

Journal of

Function Spaces

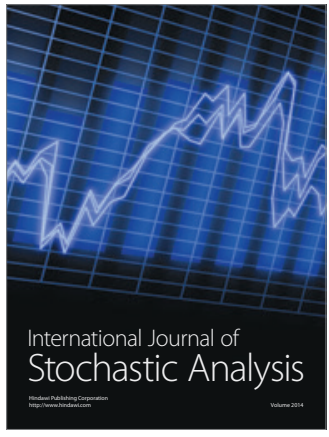

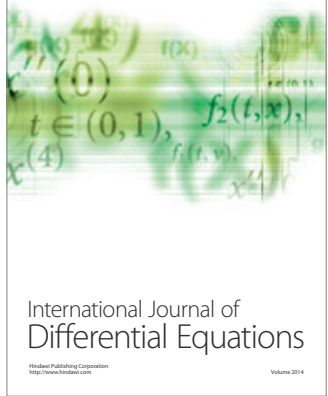
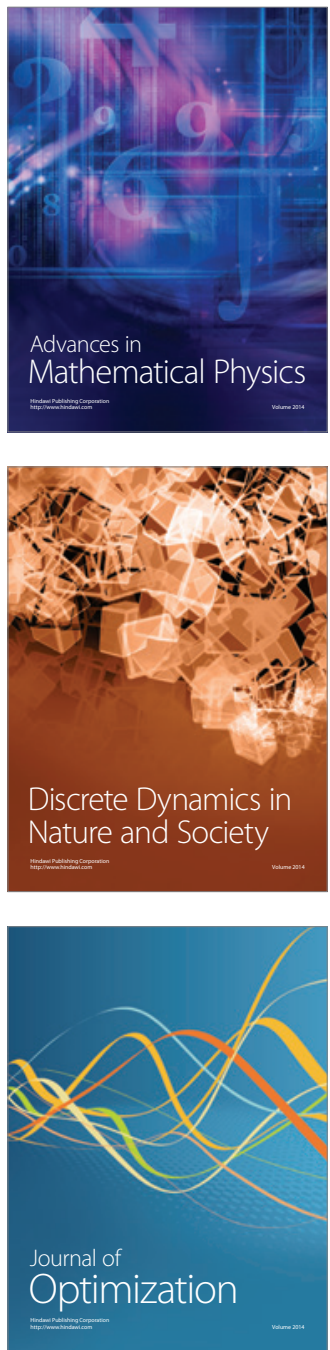